\section{Effect of crosslinker and nanostructure on adsorption and release of paraquat herbicide from different natural hydrogel nanocom- posites}

\author{
Renan da Silva Fernandes', Uilian Gabaldi Yonezawa², Marcia Regina de Moura ${ }^{3}$, Fauze Ahmad Aouada ${ }^{4}$ \\ *Corresponding author: E-mail address: faouada@yahoo.com.br
}

Abstract: Hydrogels based on natural polymers have been applied in different sectors due to their biocompatibility, biodegradability, relatively low cost, and atoxicity properties. The aim of this study was to prepare alginate/starch hydrogels crosslinked with different ions $\left(\mathrm{Mn}^{2+}, \mathrm{Zn}^{2+}\right.$ or $\left.\mathrm{Ca}^{2+}\right)$, containing zeolite or nanoclay and to evaluate the effect of crosslinker and nanostructure on adsorption and release behavior of paraquat herbicide. The hydrogels and their nanocomposites were prepared by immersing of alginate/starch, alginate/starch/ nanoclay or alginate/starch/zeolite solutions in recipients containing the crosslinker solution $\left(\mathrm{MnCl}_{2}, \mathrm{ZnCl}_{2}\right.$ or $\left.\mathrm{CaCl}_{2}\right)$ at $25^{\circ} \mathrm{C}$. All hydrogels presented good adsorption capacity, mainly the nanostructured hydrogels with nanoclay and zeolite loaded. The polar characteristics allow high interaction with paraquat molecules. The release behavior was also very interesting, being that the amount zeolite in the hydrogel nanocomposites-forming solution can control the paraquat release, indicating that these materials can be used as carrier vehicles in the controlled release system.

Keywords: Herbicide; Paraquat; Controlled Release; Nanoclay; Zeolite.

\section{Introduction}

The environmental concern due to the scarcity of fossil resources and the high pollution index caused by non-biodegradable materials, linked to the concept of sustainability, has directed researchers to focus their research on the development of renewable and ecologically materials. In this sense, the polymeric materials have gained great space in the different technological sectors, because it is chemically inert and have in their structure highly reactive groups that allow the modification of their properties, increasing their application. ${ }^{1-3}$

The use of polymers has revolutionized the market sectors by increasing agricultural productivity, food technology, medical treatments, aircraft performance and reducing fuel consumption through vehicles made of lighter materials. ${ }^{4}$ Even with this revolution, these polymers are mostly derived from fossil sources (petroleum), so efforts are being made to replace by natural polymers.

Natural polymers are macromolecules obtained from the extraction of plants, animals and natural waste such as peelings, fruit marc, and stems. It is considered renewable materials in which proteins such as collagen, gelatin, hyaluronic acid, silk and zein, and polysaccharides such as starch, sodium alginate, cellulose, chitosan; terpenes in the case of natural rubber and lipids. 4,5

The technological properties of natural polymers are numerous, allowing its application in many areas. Among these properties are biocompatibility, biodegradability, atoxicity, low cost, renewability, and availability. From these properties, there are already advances in the area of technology and food packaging, 6 in biomedical through the drug controlled delivery7 and bone regeneration, 8 in agriculture in soil water retention and agrochemicals controlled delivery 9 , and also in construction as natural soil stabilizer. ${ }^{4}$

One of the materials prepared from natural polymers that improved the applicability in the biomedicine and agriculture fields are the hydrogels. These classes of materials are characterized by absorbing a high amount of water into the interior by having three-dimensional networks, and which are formed by the crosslinking process. ${ }^{10-12}$ They can be prepared from a combination of various synthetic or natural materials and polymers, such as sodium alginate and starch.

Sodium alginate (SA) is a polysaccharide with a high capacity to form hydrogels when immersed in a solution containing di or trivalent ions. It is chemically structured by glycosidic units known as blocks. $M$ and $G$ blocks consist of molecules of $\beta-D$-mannuronic acid and $a-L$-guluronic acid, respectively, which are linked by a $(1,4)$ glycosidic bonds. ${ }^{10,13}$

Starch is also characterized as an interesting polysaccharide, mainly due to its availability and hydrophilic characteristics. Structurally consists of repetitive units of glucose in different conformations, being amylose and amylopectin. Amylose is a short-chain linear polymer in which the units of $a-D-$ glucopyranose are connected from a $1 \rightarrow 4$ glycosidic bond and is identified as the unbranched, hydrophobic part of starch. Like amylose, amylopectin is a long-chain polymer with repetitive units of a-D-glucopyranose linked to each other by a $1 \rightarrow 4$ glycosidic bond, but the effective a $1 \rightarrow 6$ bonds between the amylopectin molecules confer high ramifications, which differ one substance from another. ${ }^{14,15}$

Despite all these interesting properties, hydrogels, films or any other material based on natural polymers have precarious mechanical properties, which can limit their application in some areas. ${ }^{16,17}$ Thus, researchers are investigating the effect of the incorporation of fillers in the polymeric matrices. Among the different reinforcement agents used, clay and zeolite aluminosilicates stand out because they are also natural and mainly non-toxic. Besides the mechanical reinforcement, these materials increase the absorption capacity of the hydrogels and can control the release of actives. ${ }^{18,19}$

'PhD student (Physics and Chemistry)Universidade Estadual Paulista 'Júlio de Mesquita Filho'.

${ }^{2}$ PhD student in MATERIALS SCIENCE (concentration area: Chemistry of Materials) from Universidade Estadual Paulista Júlio de Mesquita Filho (2016). He is currently a Professor at Três Lagoas, Integrated Faculty of Três Lagoas - AEMS.

${ }_{3}^{3}$ Professor of the Postgraduate Program in Materials Science (PPGCM) Universidade Estadual Paulista - Júlio de Mesquita Filho.

${ }^{4}$ Associate Professor at the Department of Physics and Chemistry, Faculty of Engineering of Ilha Solteira (FEIS), Universidade Estadual Paulista - Júlio de Mesquita Filho since 2012. Professor of the Postgraduate Program in Materials Science (PPGCM). 
Therefore, the objective of this work was to develop hydrogels from natural alginate and starch polymers incorporated with inorganic nanostructures and to investigate the effect of the crosslinker and the zeolite and/or nanoclay on the paraquat herbicide adsorption and in vitro release behaviors.

\section{Material And Methods}

\section{Materials}

Corn starch - A4001 (Amidex ${ }^{\circledR} 4001 \mathrm{MW}=324,000 \mathrm{~g} / \mathrm{mol}$ ) and sodium alginate $(S A)(M V=85,000 \mathrm{~g} / \mathrm{mol} ; \mathrm{M} / \mathrm{G}$ ratio $=2.1)$ were obtained from Ingredion and Cromoline (Química Fina), respectively. Pure anhydrous calcium chloride $\left(\mathrm{CaCl}_{2}\right)$, manganese chloride $\left(\mathrm{MnCl}_{2}\right)$ and anhydrous zinc chloride $\left(\mathrm{ZnCl}_{2}\right.$ ) were acquired from Vetec (Química Fina, MM: $110.99 \mathrm{~g} /$ mol), Synth (MM: $197.90 \mathrm{~g} / \mathrm{mol}$ ) and Neon (MM: $136.30 \mathrm{~g} / \mathrm{mol})$, respectively. The nanostructures used were the zeolite - Clinoptilolite ZK406 H (St. Cloud Zeolite) and the nanoclay - Cloisite- $\mathrm{Na}^{+}$(Southern Clay Products $\left.^{\circledR}\right)$. All reagents were used as received without any purification.

\section{Preparations of solution}

The concentration of the polysaccharides was optimized in our previous study ${ }^{10}$ and the final concentration for sodium alginate, and starch was 1 and $2 \%$ w/v, respectively. Firstly, the starch was initially dissolved in distilled water under magnetic stirring at $70{ }^{\circ} \mathrm{C}$. Then, SA powder was solubilized into the starch solution using mechanical stirring for $4 \mathrm{~h}$. After, the final solution was stored in the refrigerator to inhibit microbial growth.

The solutions of the crosslinker agents $\left(\mathrm{MnCl}_{2}, \mathrm{ZnCl}_{2}\right.$ or $\left.\mathrm{CaCl}_{2}\right)$ were obtained in the concentrations of $1 \% \mathrm{w} / \mathrm{v}$. For this, each crosslinker agent was dissolved separately in distilled water under magnetic stirring at $25^{\circ} \mathrm{C}$.

\section{Preparation of hydrogels}

The sodium alginate/starch, alginate/starch/nanoclay or alginate/ starch/zeolite solution was separately placed in an $8 \mathrm{~cm}^{2}$ mold and immersed in a recipient containing the crosslinker solution during $24 \mathrm{~h}$. Then, the prepared hydrogel or their nanocomposite was removed from mold and added in a recipient containing distilled water for dialysis for $24 \mathrm{~h}$. Finally, the hydrogels were $40{ }^{\circ} \mathrm{C}$ oven-dried for $24 \mathrm{~h}$ and characterized.

\section{Characterizations}

\section{Paraquat $(\mathrm{PQ})$ adsorption in aqueous solution}

The herbicide adsorption behavior was analyzed by inserting a certain mass of previously dried hydrogel $(w)$ in an herbicide solution of known concentrations $\left(\mathrm{C}_{0}\right)$.

The herbicide concentrations in the solution were determined by using UV-Vis spectrophotometer at $\lambda=257 \mathrm{~nm}$ and based on the calibration curve. The herbicide amount absorbed $\left(q_{t}\right)$ was determined using Equation 1:

$$
q_{t}=\frac{\left[\left(C_{0}-C_{t}\right)\right] \times \mathrm{V}}{\mathrm{w}}
$$

where $C_{t}$ is the herbicide concentration at time " $t$ " and $V$ is the paraquat solution volume.

\section{In vitro assays herbicide release}

The PQ release behavior was studied at $\mathrm{pH} 7.4$ buffer solution (200 $\mathrm{mL}$ of $\mathrm{KH}_{2} \mathrm{PO}_{4} 8 \mathrm{~g} / \mathrm{L}$ solution $+800 \mathrm{~mL}$ of $\mathrm{K}_{2} \mathrm{HPO}_{4} 9.5 \mathrm{~g} / \mathrm{L}$ solution). The hydrogel loaded with paraquat was immersed into $20 \mathrm{~mL}$ of buffer solution. The kinetic of the $\mathrm{PQ}$ amount released was investigated by monitoring the variation of absorbance peak at $\lambda=257 \mathrm{~nm}$, using the same methodology described above. The quantity of paraquat release percentage was determined from Equation 2:

$$
\text { Paraquat released }(\%)=(\mathrm{Mt} / \mathrm{M} \infty) \times 100
$$

and $\mathrm{M} \infty$ is the total herbicide amount loaded by the hydrogel.

\section{Statistical analysis}

Statistical analysis was performed using a SISVAR software (version 5.7) by using the Tukey's tests at $95 \%$ confidence level.

\section{Results and Discussion \\ Adsorption of paraquat herbicide \\ Starch-alginate composite hydrogels}

From Figure 1, it was possible to see that the all composite hydrogels, crosslinked with different ions, have good adsorption capacity. This great affinity is mainly related to the presence of polar groups in the polymeric backbone.

As the hydrogel is constituted of an anionic polysaccharide (SA), and paraquat presents cationic characteristics, the adsorption can occur through electrostatic interactions. This interaction occurs mainly between the $-\mathrm{COO}^{-}$groups and the $\mathrm{H}_{3} \mathrm{C}-\mathrm{N}^{+}$linked to the 2 pyridinic rings of the paraquat molecule (Figure 2).

Additionally, the presence of $-\mathrm{OH}$ groups in the chemical structure of both alginate and starch polysaccharides also favored the pesticide adsorption, as well as the hydrophobic interactions..$^{20,21}$ The $\mathrm{sp}^{2}$ hybridization of the pyridinic ring becomes the structure with weakly polar characteristics whereas this hybridized form is more electronegative than $\mathrm{sp}^{3}$ hybridization, also present in the pesticide structure. This factor also improved paraquat absorption.

It is noted that the hydrogels presented the same absorption equilibrium time (approximately 10 hours of study), independently of the crosslinker agent. Additionally, the hydrogels crosslinked with $\mathrm{Mn}^{2+}$ absorbed more than those crosslinked with $\mathrm{Zn}^{2+}$ or $\mathrm{Ca}^{2+}$. This tendency is probably related to both factors: ion size and quantity of free $-\mathrm{COO}^{-}$groups. It is known that the electrostatic interactions between the crosslinker ions and $-\mathrm{COO}^{-}$groups are non-directional. As the $\mathrm{Mn}^{2+}$ ions are the smallest concerning to the others, their interaction with $-\mathrm{COO}^{-}$groups is less effective, consequently, there is a greater amount of $-\mathrm{COO}^{-}$free to interact with paraquat (Figure 2).

On the other hand, the increase in ion size promotes a more effective electrostatic interaction because the species are closer, and the - $\mathrm{COO}^{-}$ groups are no longer free to interact with the herbicide, since they are attracted by the ions to form the three-dimensional networks. ${ }^{22}$ Because it is size, there are more effective repulsive interactions between the $\mathrm{Ca}^{2+}$ ions and the cationic regions of paraquat, decreasing their adsorption.

Another interesting factor to be highlighted is the low effectiveness in the interaction of the $\mathrm{Mn}^{2+}$ and $-\mathrm{COO}^{-}$, making the chain more flexible (high expansion degree by relaxation process). This factor guarantee a sorption of greater amount of paraquat in its structure. 


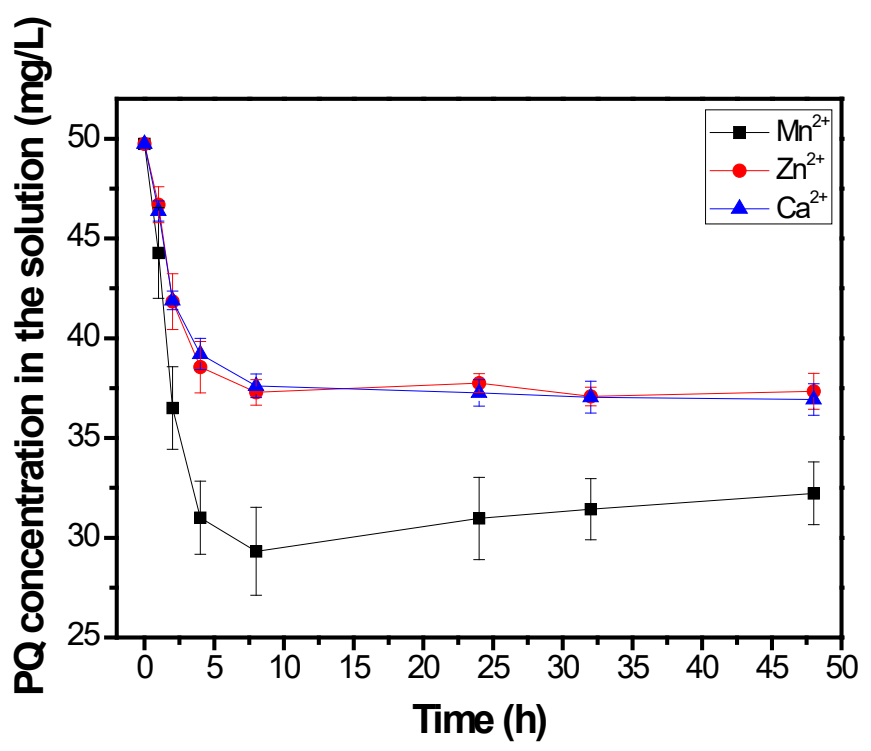

(a)

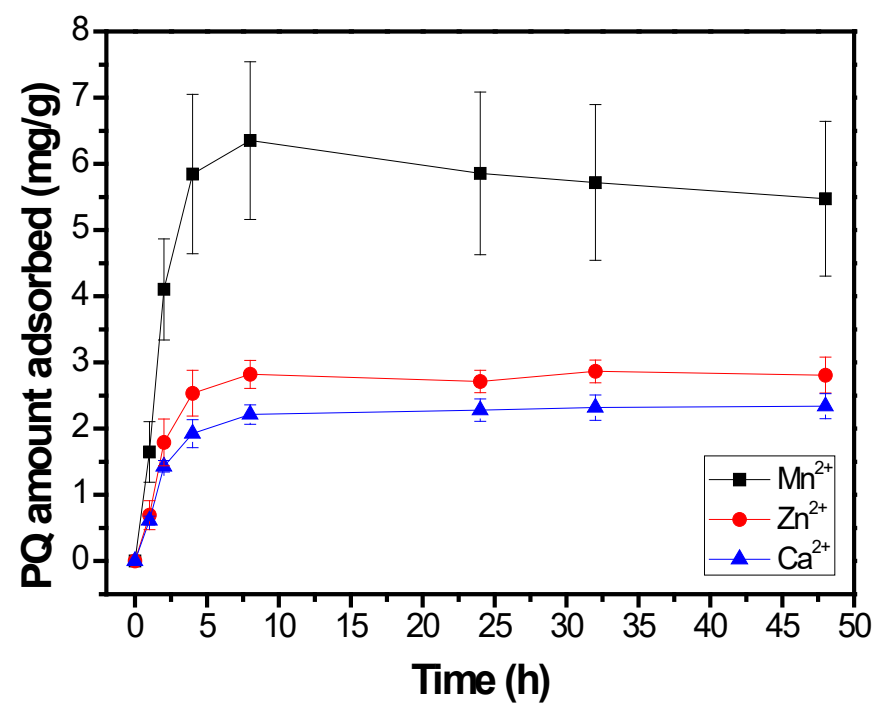

(b)

Figure 1 - Adsorption profiles of composite hydrogels. (a) paraquat concentration in the study solution, and (b) paraquat amount adsorbed in mg/g hydrogel.

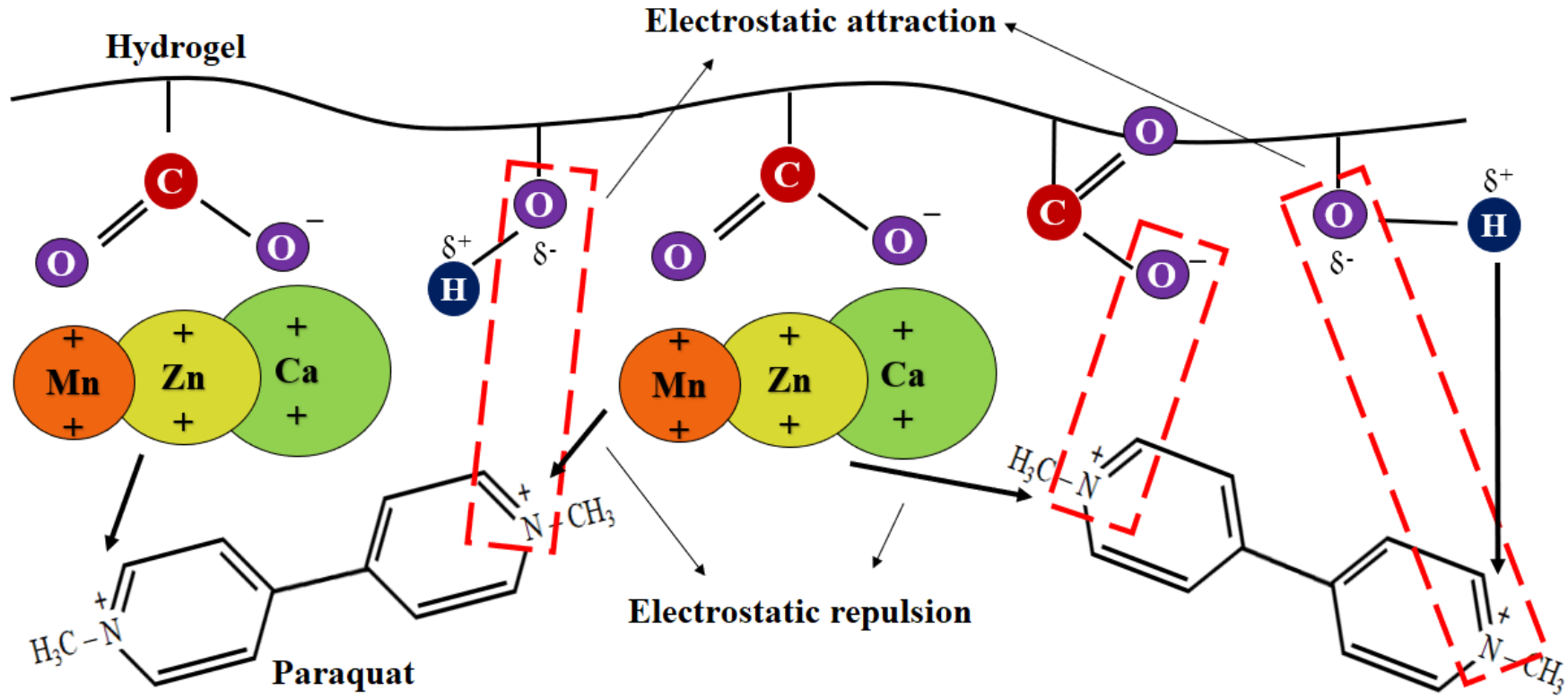

Figure 2 - Representative model of the interactions between the hydrogel matrix and the paraquat molecules.

\section{Adsorption behavior of nanocomposite hydrogels}

From Figure 3 , it was possible to confirm that the incorporation of the nanostructures significantly improves the pesticide adsorption capacity of the matrices.

In the nanocomposites, the polar characteristic of their structures is increased because the aluminosilicates (nanoclay or zeolite) have atoms with different electronegativity in its chemical structures. This difference in electronegativity creates permanent dipoles in the molecule, which are responsible for the Coulombic interaction with the paraquat molecules $\left(\mathrm{H}_{3} \mathrm{C}-\mathrm{N}^{+}\right) \cdot{ }^{23,24} \mathrm{~A}$ simple model representing theses specific interactions between nanostructure-pesticide is represented in Figure 4.
For zeolite-hydrogel nanocomposites, an important fact to be highlighted is that paraquat molecules may not have diffused between the channels of the zeolite structure because their molecules have dimensions of approximately $15 \AA$ and the zeolite pores channels have sizes around $4 \AA .{ }^{21,25}$

It is not observed a very significant effect on the adsorption capacity of nanocomposite hydrogels caused by crosslinker type. This no variation is possibly being masked by the addition of nanostructures, showing a competitive interaction sites, i.e., polymeric chains-paraquat and zeolite/nanoclay-paraquat. 
Effect of crosslinker and nanostructure...

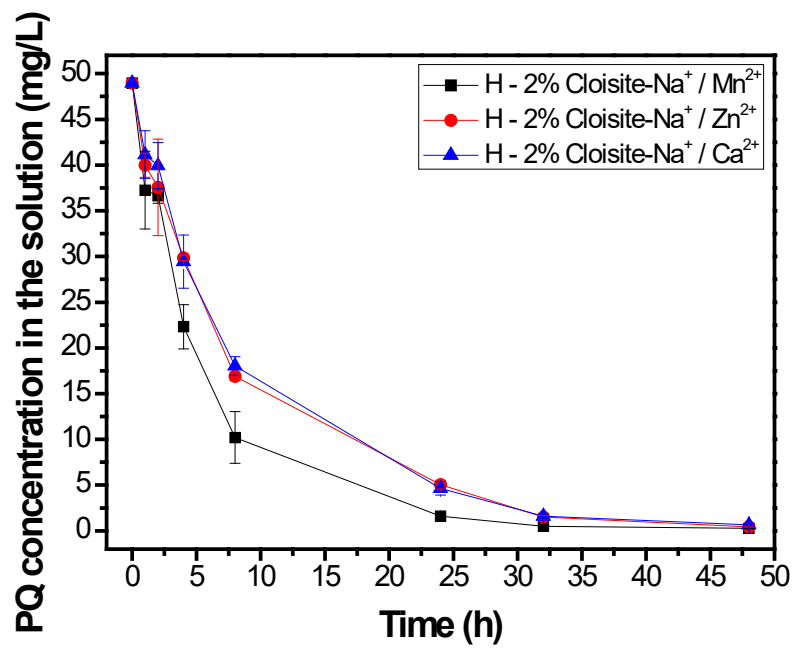

(a)

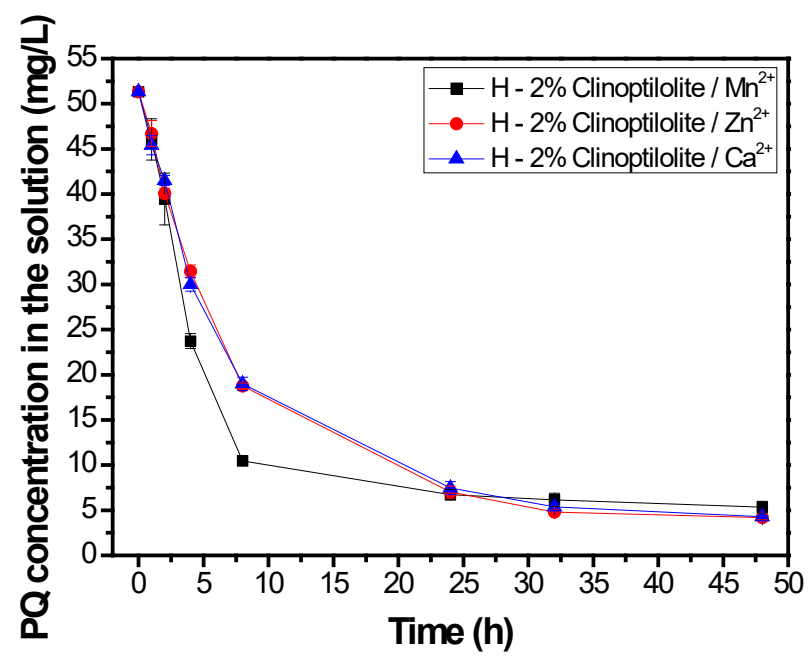

(b)

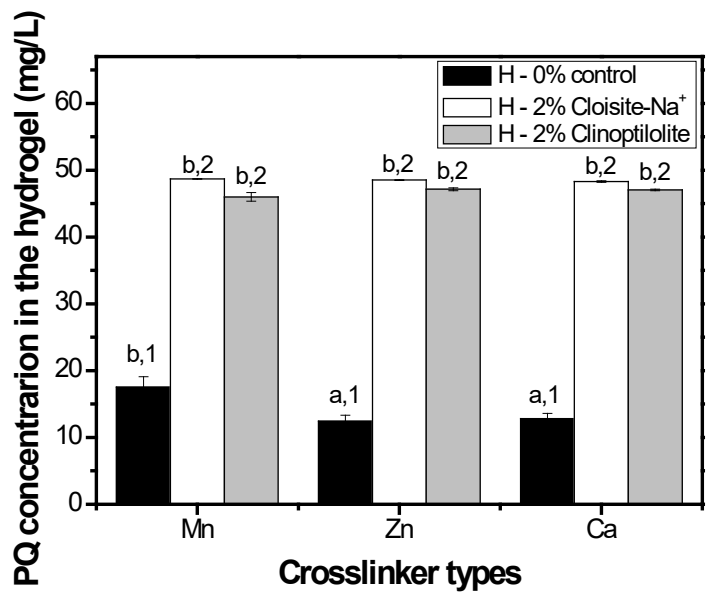

(c)

Figure 3 - Adsorption kinetic behaviors: Paraquat concentration in the solution for hydrogels incorporated with (a) nanoclay and (b) zeolite, and (c) paraquat concentration adsorbed at equilibrium for composite and nanocomposite hydrogels. Different letters and numbers indicates significant difference at $\mathrm{P}<0.05$ in the different crosslinkers and different concentration, respectively. All experiments were done in triplicate $(n=3)$. 
Fernandes et al.
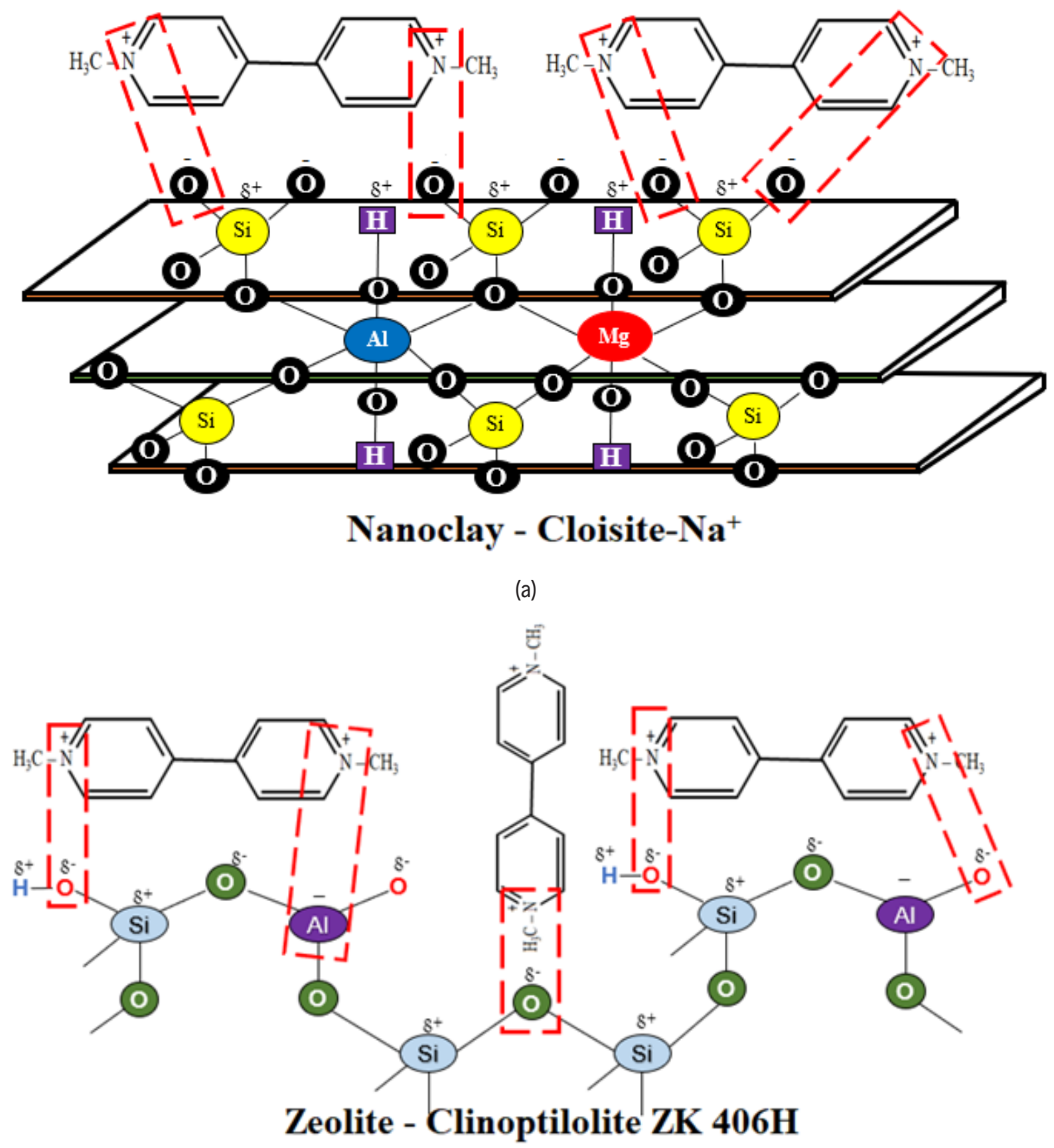

(a)

(b)

Figure 4 - Proposed model representing the electrostatic interactions between paraquat and nanostructures (a) nanoclay and (b) zeolite. 


\section{Desorption of paraquat herbicide}

\section{Composite hydrogels release behavior}

As observed in the Figure 5, the composite hydrogels reached equilibrium around 8 hours in which there was total release of the paraquat adsorbed. We believe that the amount above $100 \%$ is due to the paraquat amount that was adsorbed on the surface of the hydrogel not quantified in the removal process from the solution.

The active controlled release process from polymeric structure can occurby differentways depending on the bond type formed between these species. Thus, if they are joined by primary bonds, i.e., covalent or ionic bond, this active release must occur, mainly, by disintegration/erosion of the polymeric structure. Already when joined by physical interactions, the release occurs mainly by diffusion process, being closely influenced by the swelling capacity of the hydrogel as well as the pore sizes. ${ }^{26-28}$

It was highlighted in our previous study ${ }^{10}$ that in the swelling process the chains of composite hydrogels crosslinked with $\mathrm{Mn}^{2+}$ expands to a higher degree, due to the less effective interactions between these ions and the $-\mathrm{COO}^{-}$groups. Besides, the pore size of these supracitated hydrogels is probably larger than the hydrogels crosslinked with other ions, which facilitated the herbicide diffusion. The good solubility of paraquat in water also facilitated their diffusion to desorption medium (buffer solution at $\mathrm{pH}$ 7.4).

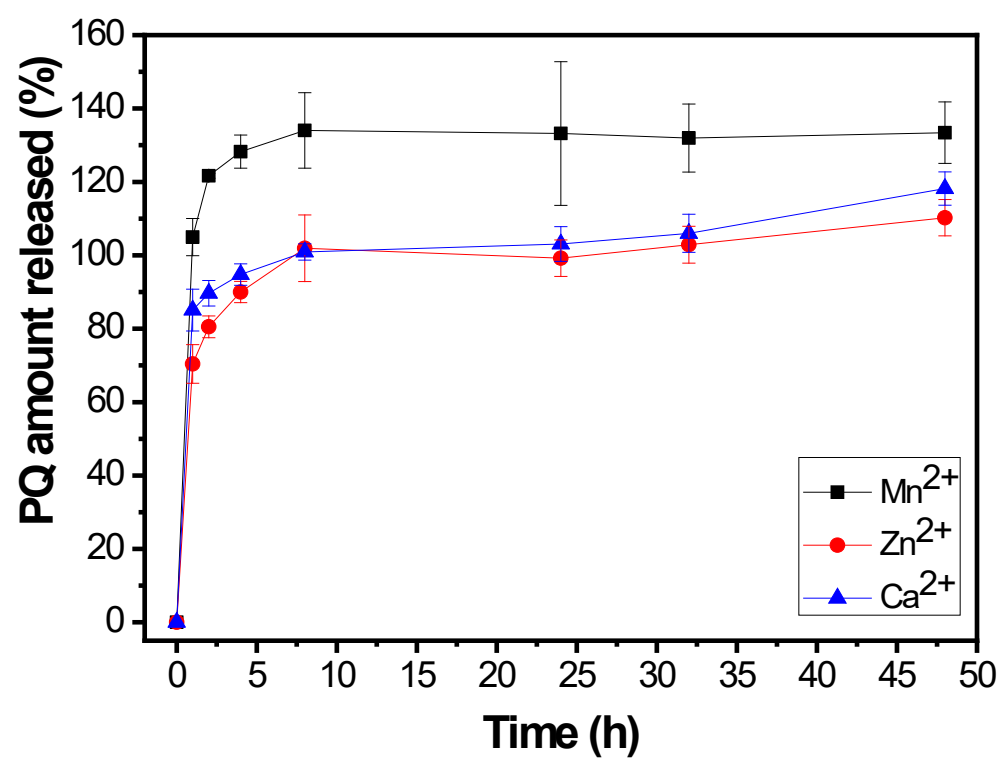

Figure $\mathbf{5}$ - Paraquat amount released in percentage from starch/sodium alginate hydrogels crosslinked with different ions.

\section{Nanocomposite hydrogels release behavior}

Regarding to nanocomposite hydrogels containing nanoclay and loaded with paraquat, no significant pesticide release was observed (Figure 6). It is believed that the low amount released may be related to the strong intermolecular interactions between the negative surface of the nanoclay platelets and paraquat. Furthermore, as previously reported, the paraquat molecules diffusion from hydrogels is mainly governed by the swelling process, which for these hydrogels is attenuated. This effect is related to the fact of the nanoclay acts as a physical crosslinker in the polymeric matrix, reducing their expansion capacity and making it more difficult for herbicide release. ${ }^{10}$

For the nanocomposites prepared from hidrogel and zeolite, it was observed a good release capacity (Figure 7). The better pesticide desorption behavior presented by hydrogels containing zeolite over nanoclay-hydrogel nanocomposites is probably related to the fact of the paraquat no penetrated into zeolite channels, since its molecules are larger than the zeolitic pores.

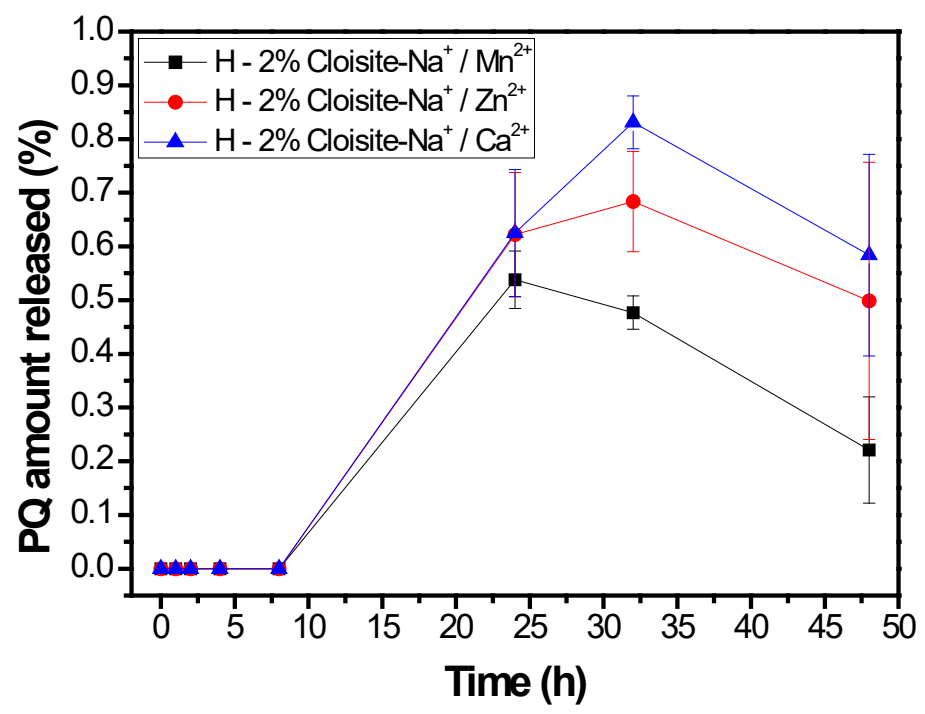

Figure 6 - Paraquat amount released in percentage from starch/sodium alginate hydrogels containing $2 \%$ nanoclay and crosslinked with different ions. 
The increase in zeolite concentration decreased the amount of paraquat released (Figure 7d) due to the increase in the quantity of polar regions that are probably interacting with the paraquat molecules. Additionally, based on the swelling results of the previous study ${ }^{10}$, both zeolite and nanoclay is acting as a physical crosslinker, what decreased the polymeric relaxation during the swelling process, reducing the amount of paraquat released from nanocomposites. Finally, the type of the crosslinker influenced the velocity of the pesticide desorption. For instance, the time for release of $20 \%$ of paraquat (Figure $7 \mathrm{~d}$ ) were $1.0 \mathrm{~h}$; $3.3 \mathrm{~h}$, and $5.2 \mathrm{~h}$ for $\mathrm{Mn}^{2+}, \mathrm{Ca}^{2+}$ and $\mathrm{Zn}^{2+}$, respectively.

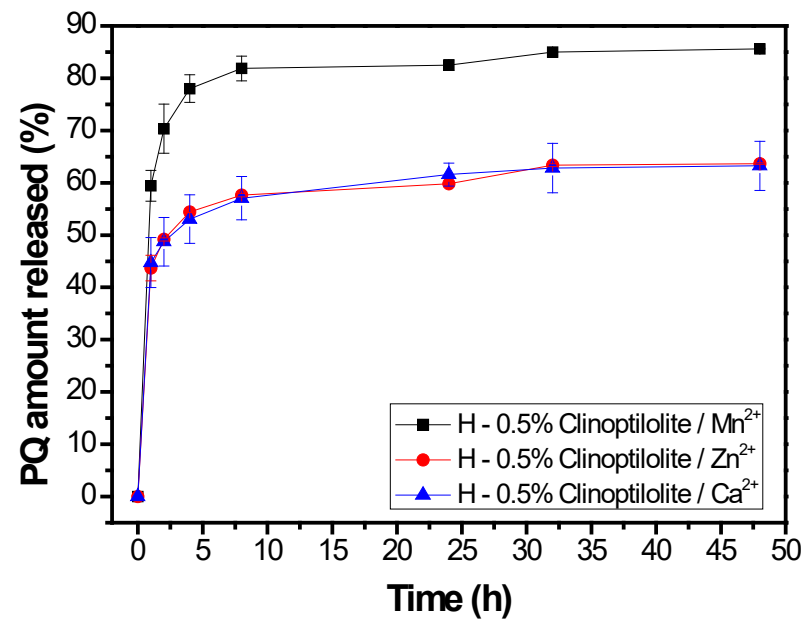

(a)

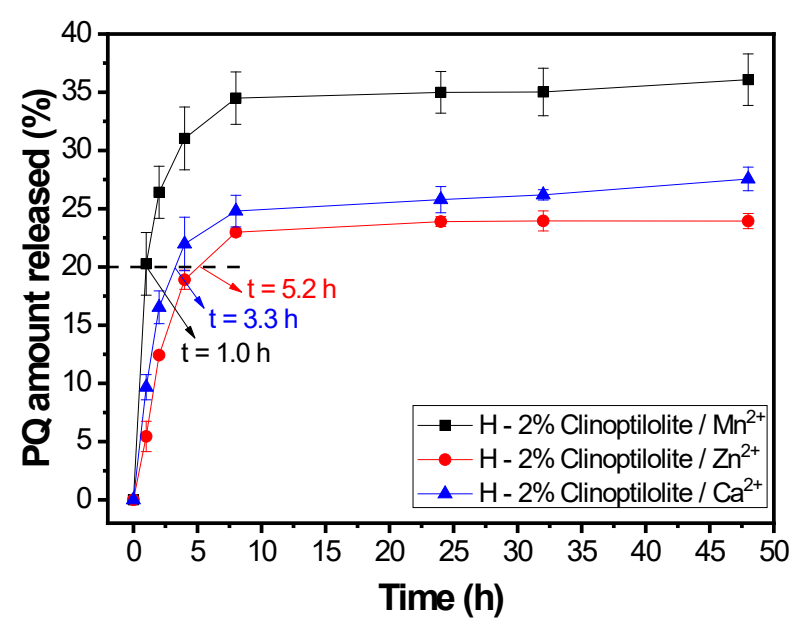

(c)

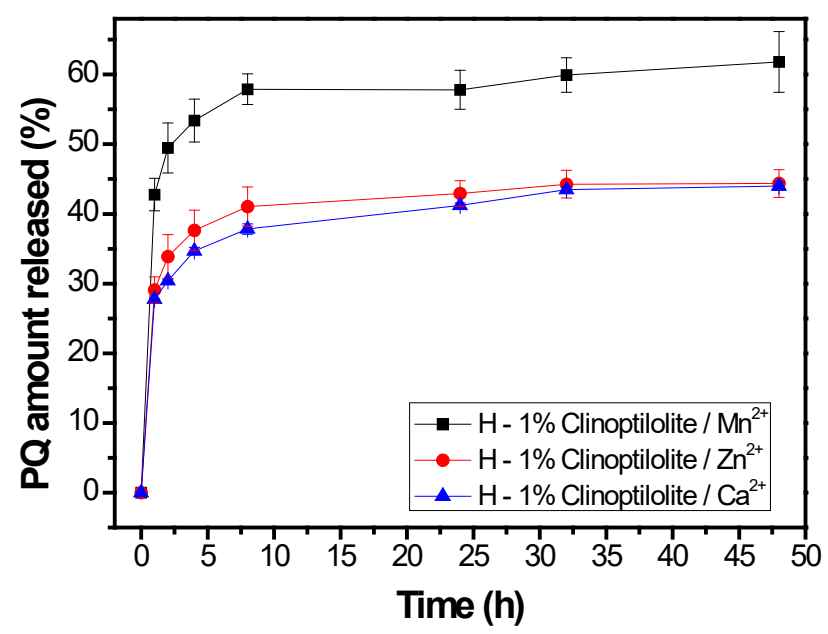

(b)

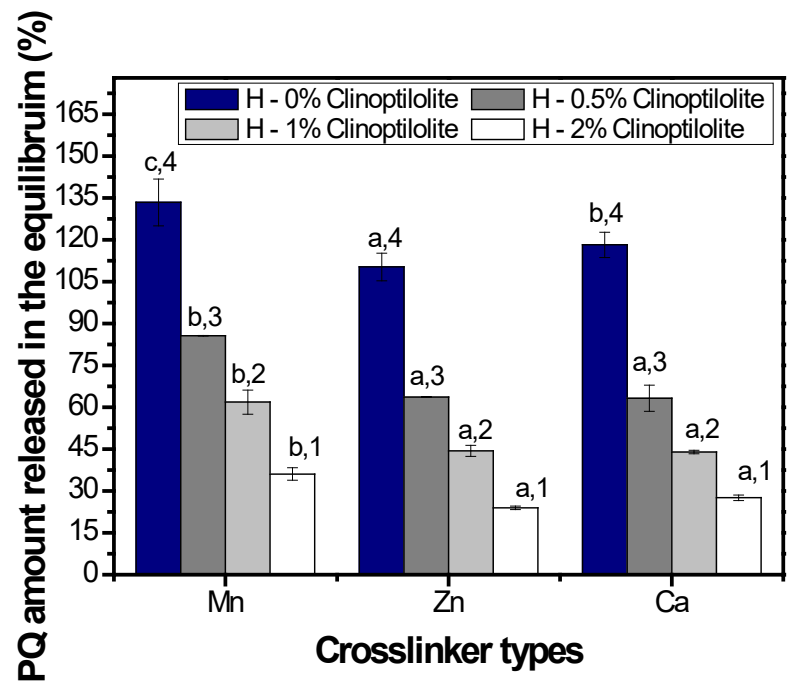

(d)

Figure 7 - Paraquat release behavior from starch/alginate hydrogels containing different zeolite concentrations. (a) $0.5 \%$ (b) $1 \%$ (c) $2 \%$ zeolite, and (d) paraquat amount released in the equilibrium stages. Different letters and numbers indicates significant difference at $P<0.05$ in the different crosslinkers and different zeolite concentration for the same crosslinker, respectively. All experiments were done in triplicate $(n=3)$.

\section{Conclusion}

The composite and nanocomposite hydrogels based on alginate and starch natural polymers were successfully obtained by ionotropic gelation using three different crosslinkers. The different sizes of the crosslinkers altered the interaction between pesticide-matrix, reflecting in different profiles of adsorption and desorption pesticide. The addition of nanostructures also increased the hydrogel adsorption capacity. In relation of nanostructures, the presence of zeolite considerably reduced the paraquat amount released. On the other hand, interactions between paraquat and nanoclay were so effective preventing the release of herbicide. The results of this study show that hydrogels can be prepared with different crosslinkers and nanostructures and thus having desired sorption and desorption properties. In this way, hydrogels and their nanocomposites can be used in controlled release systems, not only in the paraquat release, but also in the drug release, since the natural polymers used are also biocompatible and biodegradable.

\section{Acknowledgments}

The authors are grateful to Universidade Estadual Paulista, and Brazilian research financing institutions Fundação de Amparo à Pesquisa do Estado de São Paulo (CEPID - CDMF Grant 2013/07296-2) and Conselho Nacional de Desenvolvimento Científico e Tecnológico (CNPq) (MRM 312530/2018-8; FAA 312414/2018-8 and 405680/2016-3). for their financial support. This study was financed in part by Coordenação de Aperfeiçoamento de Pessoal de Nível Superior - Brasil (CAPES) - Finance Code 001".

\section{References}

1. Jr Canevarolo SV, Um texto básico para tecnólogos e engenheiros. Conceito de Polímeros. In: Ciência dos Polímeros 3. ed. São Paulo: Artiliber, 2006.

2. Guilherme MR, Aouada FA, Fajardo AR, Martins AF, Paulino AT, 
Davi MFT, Rubira AF, Muniz EC, Superabsorbent hydrogels based on polysaccharides for application in agriculture as soil conditioner and nutrient carrer: A review. Eur Polym J 72 : 365-385 (2015).

3. Lazarini SC, Lustri WR, Bacterial cellulose: Application as drug delivery system. Int J Adv Pharm Med Biotechnol 1 : 7-10 (2018).

4. Soares RMD, Siqueira NM, Prabhakaram MP, Ramakrishna S, Electrospinning and electrospray of bio-based and natural polymers for biomaterials development. Mater Sci Eng C 92 : 969 982 (2018).

5. Udawattha $\mathrm{C}$, De Silva, DE, Galkanda H, Halwatura R, Performance of natural polymers for stabilizing Earth blocks. Act Mater 2 : 2332 (2018).

6. Bashir A, Jabeen S, Gull N, Islam A, Sultan M, Ghaffar A, Khan SM, Iqbal SS, Jamil T, Co-concentration effect of silane with natural extract on biodegradable polymeric films for food packaging. Int J Biol Macromol 106 : 351-359 (2018).

7. Sabale V, Paranjape A, Patel V, Sabale P, Characterization of natural polymers from jackfruit pulp, calêndula flowers and tara seeds as mucoadhesive and controlled release componentes in buccal tablets. Int J Biol Macrmol 95 : 321-330 (2017).

8. Ragunathan S, Govindasamy G, Raghul DR, Karuppaswamy M, VijayachandraTogo RK, Hydroxyapatite reinforced natural polymer scaffold for bone tissue regeneration. Mater Today-Proc In Press (2019).

9. Saruchi, Kumar V, Mittal H, Alhassan SM, Biodegradable hydrogels of tragacanth gum polysaccharide to improve water retention capacity of soil and environment-friendly controlled release of agrochemicals. Int J Biol Macromol 132 : 1252-1261 (2019).

10. Fernandes RS, Tanaka FN, De Moura MR, Aouada FA, Development of alginate/starch-based hydrogels crosslinked with different ions: hydrophilic, kinetic and spectroscopic properties. Mater Today Commun 21 : 100636 (2019)

11. Chitra G, Franklin DS, Sudarsan S, Sakthivel M, Guhanathan S, Noncytotoxic silver and gold nanocomposite hydrogels with enhanced antibacterial and wound healing application. Polym Eng Sci 58 : 2133-2142 (2018)

12. Carbinatto FM, Sábio RM, Meneguin AB, Cestari SE, Cruz SA, Barud HS, Bacterial cellulose-based hydrogels for wound healing: characterization and in vitro evaluation. Int J Adv Pharm Med Biotechnol 1 : 21-30 (2018).

13. Fernandes RS, De Moura, MR, Glenn GM, Aouada FA, Thermal, microstructural, and spectroscopic analysis of $\mathrm{Ca}^{2+}$ alginate/clay nanocomposite hydrogel beads. J Mol Liq 265 : 327-336 (2018).

14. Seok JY, Lee DJ, Lim ST, Reddy CK, Preparation and characterization of inclusion complexes between debranched maize starches and conjugated linoleic acid. Food Hydrocoll 96 : 503-509 (2019).

15. Mahmood K, Kamilah H, Shang PL, Sulaiman S, Ariffin F, Alias AK, A review: Interaction of starch/non-starch hydrocolloid blending and the recent food applications. Food Biosci 19 : 110-120 (2017).

16. Belibi PC, Daou TJ, Ndjaka JMB, Michelin L, Brendlé J, Nsom B, Durand $B$, Tensile and water barrier properties of cassava starch composite films reinforced by synthetic zeolite and beidellite. J Food Eng 115 : 339-346 (2013).

17. Martins M, Barros AA, Quraishi S, Gurikov P, Raman SP, Smirnova I, Duarte ARC, Reis RL, Preparation of macroporous alginate-based aerogels for biomedical applications. J Supercrit Fluid 106 : 152-
159 (2015).

18. Wang $\mathrm{Q}$, Wang $\mathrm{Y}$, Chen $\mathrm{L}, \mathrm{A}$ green composite hydrogel based on cellulose and clay as efficient absorbent of colored organic effluent. Carbohyd Polym 210 : 314-321 (2019).

19. Chen Y, Kang S, Yu J, Wang Y, Zhu J, Hu Z, Tough robust dual responsive nanocomposite hydrogel as controlled drug delivery carrier of aspirin. J Mech Behav Biomed Mater 92 : 179-187 (2019).

20. De Moraes MA, Vasconcellos FC, Fraceto LF, Beppu MM, Chitosan and alginate biopolymer membranes for remediation of contaminated water with herbicides. J Environ Manage 131 : 222 -227 (2013).

21. Barbosa DHO, De Moura MR, Aouada FA, Polysaccharide-based nanocomposite hydrogels with zeolite: Evaluation of the sorption process of pesticide paraquat. Quím Nova 41 : 380 - 385 (2018).

22. Etcheverry M, Cappa V, Trelles J, Zanini G, Montmorillonitealginate beads: Natural mineral and biopolymers based sorbent of paraquat herbicides. J Environ Chem Eng 5 : 5868 - 5875 (2017).

23. Pukcothanung $Y$, Siritanon T, Rangsriwatananon $K$, The efficiency of zeolite $Y$ and surfactante-modified zeolite $Y$ for removal of 2,4-diclorophenoxyacetic acid and 1,1'-dimethyl-4,4'bipyridinium ion. Micropor Mesopor Mat 258 : 131 - 140 (2018).

24. Garcia JAF, Síntese e caracterização de novos bionanocompósitos híbridos constituídos por polissacarídeos carboximetilcelulose e nanoargila com possível aplicação para remoção ou liberação controlada de defensivo agrícola paraquat. 2018. $117 \mathrm{f}$. Dissertação (Mestrado em Ciência dos Materiais) - Departamento de Física e Química, Universidade Estadual Paulista "Júlio de Mesquita Filho", Ilha Solteira, SP, 2018.

25. Koh SM, Dixon JB, Preparation and application of organo-minerals as sorbents of phenol, benzene and toluene. Appl Clay Sci. 18 : $111-122$ (2001).

26. Silva MS, Concenza DS, Grillo R, De Melo NFS, Tonello PS, De Oliveira LC, Cassimiro DL, Rosa AH, Fraceto LF, Paraquat-loaded alginate/chitosan nanoparticles: Preparation, characterization and soil sorption studies. J Hazard Mater 190 : 366 - 374 (2011).

27. Aouada FA, De Moura MR, Mattoso LHC, Biodegradable hydrogel as delivery vehicle for the controlled release of pesticide. In: Stoytcheva, M. ed by Pesticides-Formulations, Effects, Fate. InTech, Rijeka, pp 81-102 (2011).

28. Jampílek J, Král'ová K, Nanopesticide: Preparation, targeting and controlled release. In: New Pesticides and Soil Sensors. ed by Elsevier. pp 81 -127 (2017). 